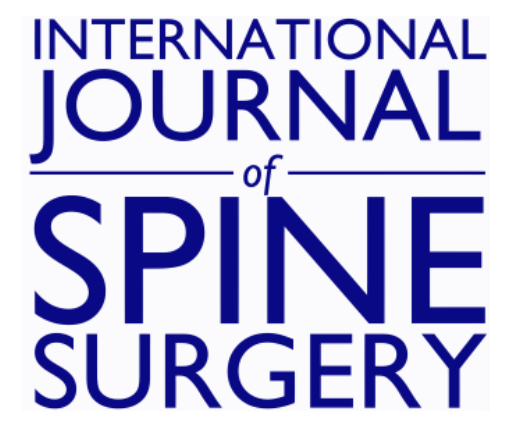

\title{
The effect of July admission on inpatient morbidity and mortality after adult spinal deformity surgery
}

Rafael De la Garza-Ramos, Peter G. Passias, Frank J. Schwab, Virginie Lafage and Daniel M. Sciubba

Int J Spine Surg 2016, 10 ()

doi: https://doi.org/10.14444/3003

http://ijssurgery.com/content/10/3

This information is current as of April 26, 2023.

Email Alerts Receive free email-alerts when new articles cite this article. Sign up at:

http://ijssurgery.com/alerts

The International Journal of Sbinesurgerth 2397 Waterbury Circle, Suite 1,

Aurora, IL 60504, Phone: +1-630-375-1432

(C) 2016 ISASS. All Rights Reserved. 


\section{The effect of July admission on inpatient morbidity and mortality after adult spinal deformity surgery}

Rafael De la Garza-Ramos, MD, ${ }^{1}$ Peter G. Passias, MD, ${ }^{2}$ Frank J. Schwab, MD, ${ }^{3}$ Virginie Lafage, Ph.D, ${ }^{3}$ Daniel M. Sciubba, $M D^{1}$

${ }^{1}$ Department of Neurosurgery, Johns Hopkins University School of Medicine, Baltimore, Maryland, 2Division of Spinal Surgery, NYU Medical CenterHospital for Joint Diseases, New York City, New York, ${ }^{3}$ Spine Surgery, Hospital for Special Surgery, New York City, New York

\section{Abstract}

Background

Some studies have suggested patients who undergo surgery in July have worse outcomes compared to patients treated during other months. The purpose of this study is to compare inpatient morbidity and mortality among patients who underwent adult spinal deformity (ASD) surgery in July with those who underwent surgery in other months.

Methods

Admission data for patients who underwent ASD surgery were extracted from the Nationwide Inpatient Sample for the years 2002 to 2011. Only adult patients (over 21 years of age) and elective admissions to teaching hospitals were included. A multivariable regression analysis was performed to examine the independent effect of July admissions on overall complications, major complications, and inpatient mortality.

Results

A total of 27,794 patients were identified, with 2,023 (7.8\%) admitted in July and 25,771 (92.2\%) in other months. Overall complication rates in July (43.1\%) were not different from rates in other months $(44.9 \%, \mathrm{p}=0.468)$. Similarly, major complication rates were similar; $12.9 \%$ in July and $12.4 \%$ in other months ( $\mathrm{p}=0.764)$. Mortality was not different between groups $(\mathrm{p}=0.807)$. After multivariable analysis, July admissions were not found to increase the odds of developing any complication (OR 0.94; 95\% CI, 0.77 - 1.12; $\mathrm{p}=0.403$ ), major complications (OR 1.04; 95\% CI, 0.76 - 1.41; $\mathrm{p}=0.788)$ or inpatient mortality (OR 1.35; 95\% CI, $0.31-5.84 ; \mathrm{p}=0.684)$.

Conclusion

In this study of a nationwide database, patients who underwent ASD surgery in July did not have increased odds of developing a complication or inpatient mortality compared to patients admitted in other months.

KEYWORDS: JULY EFFECT, ADULT SPINAL DEFORMITY, TEACHING HOSPITAL, COMPLICATIONS, MORTALITY, NATIONWIDE INPATIENT SAMPLE VOLUME 10 ARTICLE 3 DOI: 10.14444/3003

\section{Introduction}

The academic year at teaching hospitals in the United States begins at most programs every July, when new interns, upcoming senior residents, and fellows assume increased responsibility in patient care. This influx of new staff has been proposed to be a potential source for increased medical errors and adverse effects affecting patient outcomes, in what is colloquially known as the "July effect". $1-11$ While some studies have shown no difference in short-term outcomes (i.e. morbidity or mortality) for patients treated in July, other studies have found higher rates of medical errors and mortality during this month. ${ }^{2,3,7,12}$
Corrective surgery for adult spinal deformity (ASD) is a fairly morbid and technically-demanding procedure. Complication rates range from $40-86 \%,{ }^{13,14}$ and "major" complications such as myocardial infarction, neurological injury, coagulopathy, excessive bleeding, pneumonia, sepsis, death, and others may occur. ${ }^{15}$ Spinal reconstruction for ASD oftentimes requires long operative times, instrumentation of multiple spinal segments, and complex techniques such as osteotomy. Though several studies have investigated the "July effect" on spinal surgery outcomes, ${ }^{2,6,11}$ no study has specifically examined this for ASD cases. Thus, the purpose of this article is to investigate the perioperative outcomes of patients with ASD who undergo corrective surgery at teaching 
hospitals in July compared to patients admitted in other months.

\section{Methods}

Data source and acquisition

This study utilized the Nationwide Inpatient Sample (NIS) databases for the years 2002 - 2011. NIS is the largest all-payer inpatient database in the United States, and contains discharge data from a $20 \%$ sample of community hospitals in the country. Patients with a discharge diagnosis of adult spinal deformity were identified by use of the following International Classification of Disease 9th Edition (ICD-9) codes: acquired postural kyphosis (737.10), kyphosis not elsewhere classified (737.19), acquired postural lordosis (737.20), idiopathic scoliosis and kyphoscoliosis (737.30), progressive infantile idiopathic scoliosis (737.32), thoracogenic scoliosis (737.34), scoliosis not elsewhere classified (737.39), kyphosis from secondary cause (737.41), lordosis from secondary cause (737.42), and kyphoscoliosis from secondary cause (737.43). Only patients who underwent thoracolumbar spinal fusion (81.04 - 81.09) were included (Figure 1). Patients under the age of 21 , non-elective admissions, admissions to nonteaching hospitals, and patients missing data on month of admission were excluded. According to the NIS, a hospital achieves teaching status if it meets any of the following: it has an American Medical Association approved residency program, is member of the Council of Teaching Hospitals, and/or has a ratio of interns and residents to beds of 0.25 or higher (https://www.hcupus.ahrq.gov/db/vars/hosp_teach/nisnote.jsp).

Admission information such as patient age, gender, race, primary payer, and medical comorbidities were gathered. Comorbidities were assessed as a compound score as described by Elixhauser et al. ${ }^{16}$ Operative data such as fusion of 8 or more segments, osteotomy, and revision procedures were also identified by use of ICD-9 codes. Complex cases were defined as such if they involved osteotomy, fusion of 8 or more spinal levels, revision procedures, and/or patients with a comorbidity score equal to or greater than 3.

\section{Outcome variables}

Outcomes examined in this study included overall complications, major complications, and inpatient mortality. Complications included acute posthemorrhagic anemia (285.1), postoperative shock (998.00 998.09), implant-related complications (996.2, 996.40, 996.42, 996.47, 996.49, 996.63, 996.66, 996.67, 996.75, 996.78, and 996.79), neurological complication (997.00 - 997.09), acute respiratory failure $(518.5$ - 518.53, 518.81, 518.84, 997.3), deep vein thrombosis (DVT)/pulmonary embolism (PE) (453.4 - 453.42, 453.8, 453.9, 415.22, 415.13, and 415.19), accidental puncture (998.2), hemorrhage/ hematoma (998.11 - 998.13), wound complications (998.83, 998.32, 998.51, 998.59, and 998.6), acute kidney injury (584.5 - 584.9), myocardial infarction (410.0 - 410.91), pneumonia (481, 482, and 483), iatrogenic stroke (997.02), pancreatitis (557.0), and reintubation (96.04). Major complications included shock, DVT/PE, neurological complication, sepsis, pneumonia, myocardial infarction, acute kidney injury, iatrogenic stroke, pancreatitis, acute respiratory failure, and reintubation..$^{15}$

\section{Statistical analysis}

Patient characteristics and operative covariates were compared between patients admitted in July and oth-

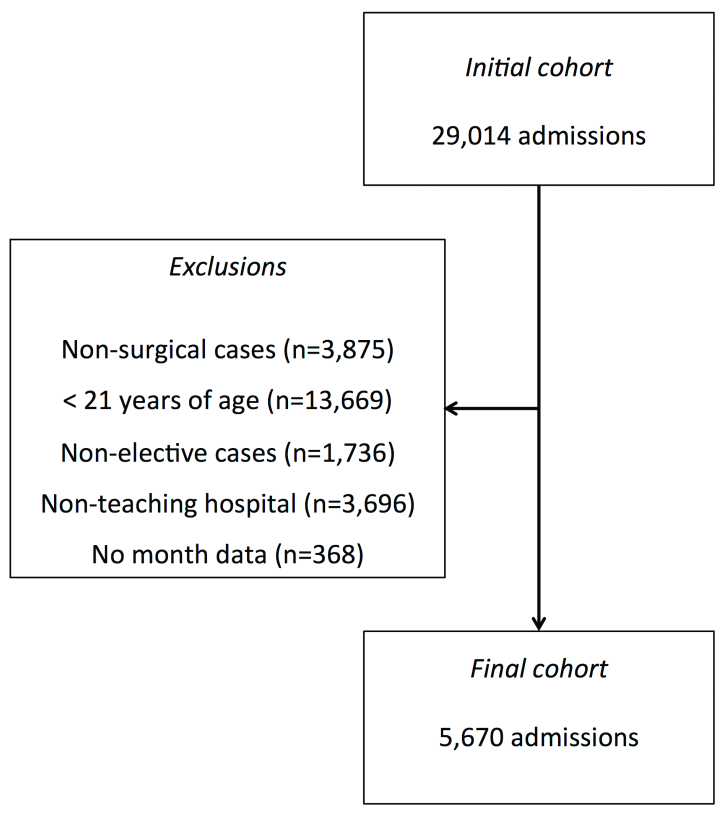

Fig. 1. Patient inclusion/exclusion criteria. Following identification of the final cohort, discharge weights were applied, which roughly correspond to a 5 -fold multiplication (given that the NIS is a $20 \%$ sample database). 
er months using two-tailed t-tests or chi-squared tests as appropriate. Discharge weights (supplied by NIS) were applied to each discharge to produce national estimates. A stepwise multivariable regression analysis was performed to examine the effect of July admission on overall complications, major complications, and mortality. This analysis controlled for any significant differences between groups in terms of patient age, gender, race, primary payer, comorbidities (alcohol abuse, deficiency anemia, chronic blood loss, congestive heart failure, chronic lung disease, coagulopathy, diabetes, liver disease, obesity, acquired immunodeficiency syndrome, drug abuse, hypertension, and renal failure), number of levels fused, osteotomy, and revision status. Results are presented as odds ratio (OR) with $95 \%$ confidence intervals (CI). All analyses were done using STATA SE (StataCorp LP, College Station, Texas). Statistical significance was set at $\alpha=0.05$.

\section{Results}

A total of 27,794 patients were identified (after application of discharge weights) who underwent ASD surgery between 2002 and 2011; there were 2,023 (7.8\%) admissions in July. General patient characteristics are summarized in Table 1 and compared between groups. Patients treated in July were significantly younger ( $56 \pm 16$ years) when compared to patients treated any other month $(58 \pm 15$ years, $\mathrm{p}=0.040$ ). However, the proportion of patients over the age of 65, gender, race, and insurance status were not significantly different between groups. The average Elixhauser score was $1.8 \pm 1.7$ for patients treated in July and $1.8 \pm 1.6$ for patients treated any other month $(\mathrm{p}=0.644)$.

The only operative parameter significantly different between groups was the proportion of patients who underwent fusion of 8 or more segments; $25.4 \%$ in July and $20.9 \%$ in other months $(\mathrm{p}=0.031)$. Overall complications were not significantly different between July admissions (43.1\%) and other months (44.9\%, $\mathrm{p}=0.468$, Table 2). Similarly, major complication rates were similar between groups; $12.9 \%$ in July versus $12.4 \%$ in other months $(\mathrm{p}=0.764)$. When examining morbidity rates stratified by month of admission, there were no differences in rates of overall complications $(\mathrm{p}=0.348)$ or major complications $(\mathrm{p}=0.974)$ (Figure 2$)$. Mortality rates were also not significantly different between patients admitted in July and other months $(\mathrm{p}=0.807)$.

Following multivariable analysis, July admissions did not increase the odds of developing any complication (OR 0.94; 95\% CI, 0.77 - 1.12; $\mathrm{p}=0.403$ ), major com-

\begin{tabular}{|c|c|c|c|}
\hline Variable & July & Other months & p-value \\
\hline Total & 2,023 & 25,771 & \\
\hline Age (average years) & $56 \pm 16$ & $58 \pm 15$ & 0.040 \\
\hline Age $>65(\%)$ & 30.4 & 35.0 & 0.057 \\
\hline Female gender $(\%)$ & 76.3 & 74.7 & 0.468 \\
\hline Race & & & \\
\hline Caucasian $(\%)$ & 91.4 & 91.3 & \multirow{4}{*}{0.933} \\
\hline African American (\%) & 3.8 & 3.5 & \\
\hline Hispanic (\%) & 1.7 & 2.2 & \\
\hline Other $(\%)$ & 3.1 & 3.0 & \\
\hline \multicolumn{4}{|l|}{ Primary payer } \\
\hline Medicare (\%) & 38.5 & 41.7 & \multirow{4}{*}{0.183} \\
\hline Medicaid (\%) & 7.2 & 4.5 & \\
\hline Private insurance (\%) & 50.2 & 50.1 & \\
\hline Other $(\%)$ & 4.1 & 3.7 & \\
\hline Elixhauser comorbidity score (average) & $1.8 \pm 1.7$ & $1.8 \pm 1.6$ & 0.644 \\
\hline Fusion of 8 or more segments (\%) & 25.4 & 20.9 & 0.031 \\
\hline Osteotomy (\%) & 6.7 & 7.1 & 0.768 \\
\hline Revision procedures (\%) & 5.0 & 4.9 & 0.933 \\
\hline
\end{tabular}

Table 2. Outcomes of patients who underwent adult spinal deformity surgery in July and other months between 2002 and 2011.

\begin{tabular}{|l|r|r|r|}
\hline Variable & July & Other months & p-value \\
\hline Total & 2,023 & 25,771 & \\
\hline Length of stay (average days) & $7.2 \pm 5.4$ & $7.3 \pm 7.1$ & 0.641 \\
\hline Overall complications (\%) & 43.1 & 44.9 & 0.468 \\
\hline Major complications (\%) & 12.9 & 12.4 & 0.764 \\
\hline Mortality (\%) & $*$ & 0.4 & 0.807 \\
\hline *NIS does not allow publication of values equal to or less than 10. & \\
\hline
\end{tabular}


plications (OR 1.04; 95\% CI, $0.76-1.41 ; \mathrm{p}=0.788$ ) or inpatient mortality (OR 1.35; 95\% CI, $0.31-5.84$; $\mathrm{p}=0.684$ ). These analyses controlled for any possible confounding factor, including patient age, gender, race, insurance status, number of segments fused, osteotomy, revision status, and comorbidities.

\section{July - August subanalysis}

Given that some spine fellowship academic programs begin training in August, a combined July-August subanalysis was performed. Crude complication rates in July-August were $43.3 \%$, compared to $45.1 \%$ in other months $(\mathrm{p}=0.335)$; major complication rates were $12.4 \%$ in July-August and $12.5 \%$ in other months $(\mathrm{p}=0.932)$; mortality rates were $0.3 \%$ in July-August and $0.4 \%$ in other months $(\mathrm{p}=0.638)$. Following multivariable analysis, July-August admissions did not increase the odds of developing any complication (OR 0.93; 95\% CI, 0.81 - 1.08; $\mathrm{p}=0.402$ ), major complications (OR 1.00; 95\% CI $0.81-1.25$; $\mathrm{p}=0.950)$, or inpatient mortality (OR $0.79 ; 95 \%$ CI $0.23-2.67$; $\mathrm{p}=0.702$ ).
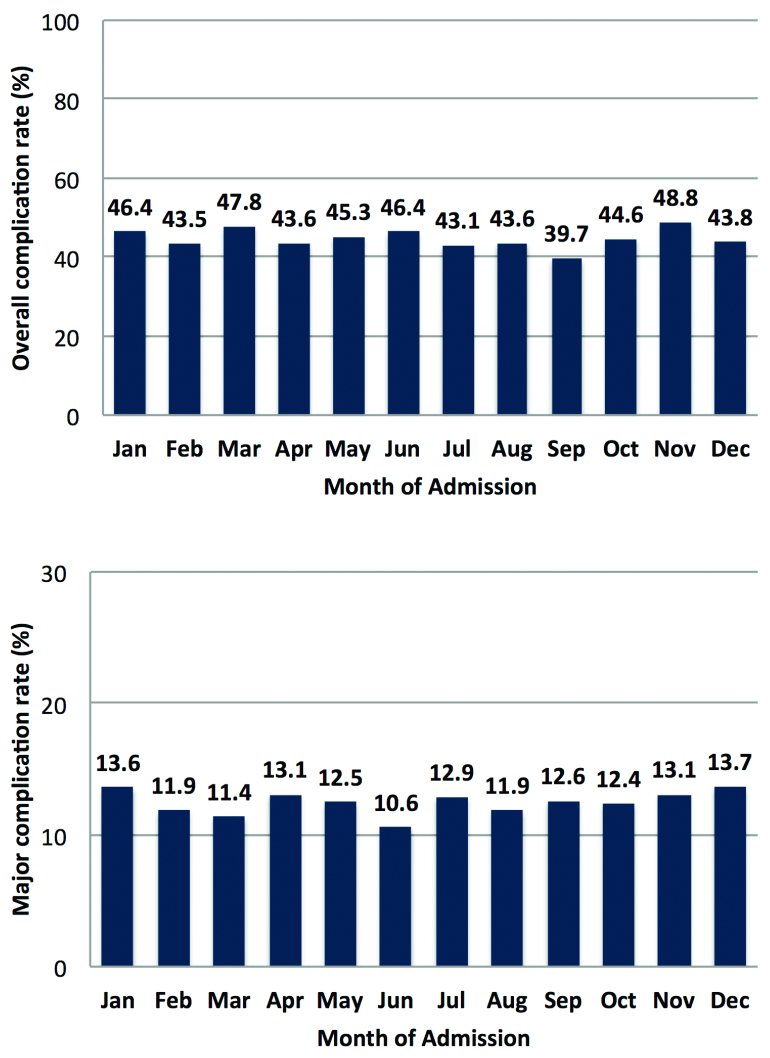

Fig. 2. Bar graphs showing rates of overall complications (Top) and major complications (Bottom) stratified by month of admission. These rates were not statistically different between groups.

\section{Complex case subanalysis}

A total of $48.2 \%$ of cases were defined as "complex", which involved osteotomy, fusion of 8 or more spinal levels, revision procedures, and/or patients with a comorbidity score of 3 or greater; $50 \%$ in July and $48.0 \%$ in other months $(\mathrm{p}=0.440)$. Complication rates for these procedures were $55.0 \%$ in patients admitted in July and $54.4 \%$ in patients admitted other months. Major complications occurred in $18.7 \%$ of patients admitted in July and $16.9 \%$ in other months $(p=0.502)$. Lastly, mortality occurred in $1.0 \%$ of cases in July and $0.5 \%$ in other months $(\mathrm{p}=0.408)$. After multivariable analysis, July admissions did not increase the odds of developing any complication (OR 1.02; 95\% CI, 0.76 - 1.36; $\mathrm{p}=0.891$ ), major complications (OR 1.15; 95\% CI, $0.79-1.67$; $\mathrm{p}=0.463)$, or inpatient mortality (OR 2.06; 95\% CI, 0.45 - 9.45; $\mathrm{p}=0.350$ ) in patients undergoing complex procedures.

\section{Discussion}

The so-called "July effect" has been widely examined in the medical literature. . $^{1-3,6,8,11}$ Every July new residents and fellows start their training at teaching hospitals in the United States, and this phenomenon has been suggested as a potential source of increased error and complications for patients treated by the "new" staff.6 Though some studies have suggested the "July effect" does exist, ${ }^{2,3}$ others have found no difference in outcomes for patients treated in July versus other months. ${ }^{1,6,8,11}$

In this study, we investigated whether patients undergoing surgery for ASD in July had different rates of inpatient morbidity and mortality when compared to patients treated in other months. After analysis of over 27,000 patients, it was found that crude overall complication rates, major complication rates, and mortality rates were not found to be significantly different between groups. Likewise, a multivariable analysis that controlled for patient characteristics, operative parameters, and comorbidities found no increased odds of adverse events for patients treated in July.

Similar to the present findings, $\mathrm{McD}$ onald et al. examined over 500,000 spinal procedures performed at 
teaching hospitals between 2001 and 2008, and found no evidence of increased complications for patients admitted in July. ${ }^{6}$ However, that study differed from the present one in various ways. First, McDonald et al. did not stratify patients based on preoperative diagnosis, and included patients with degenerative spine disease, spinal tumors, spinal infections, deformity, and others. Second, they included both elective and non-elective admissions. Lastly, they only examined mortality, discharge disposition, surgical site infection, wound dehiscence, and implant complications. Though results were similar to our findings, the present study specifically investigated whether the July effect exists for ASD patients, and 16 unique complications were examined.

In a similar study, Hoashi et al. performed a retrospective multicenter review of 575 patients who underwent surgery for adolescent idiopathic scoliosis. ${ }^{11}$ The authors found no preoperative differences between patients based on the month of surgery, including preoperative Cobb angles and Scoliosis Research Society-22 scores. Following surgery, there were no significant differences in intraoperative blood loss, operative time, total complications, or major complications based on the month of admission. The authors of that study concluded: "our results support the finding that the participation of physicians-in-training in surgery for adolescent idiopathic scoliosis does not have a season-dependent impact on patient outcomes." 11

In contrast to these previous findings, Dasenbrock et al. found that patients who underwent surgery for spinal metastatic disease in July had higher rates of inpatient morbidity and mortality compared to other months. ${ }^{2}$ The authors examined 2,920 admissions, and found a $7.5 \%$ mortality rate in July compared to 4.3\% in August and June. ${ }^{2}$ Similarly, a multivariable analysis revealed increased odds of in-hospital death (OR 1.81; 95\% CI, 1.13 - 2.91) and intraoperative complication development (OR 2.11; 95\% CI, 1.41 3.17). ${ }^{2}$ There are several possible explanations for the difference in findings between that study and ours. Patients with metastatic disease are usually sicker and may require more urgent care than patients undergoing elective ASD surgery, making them prone to medical errors and complications.
The overall inpatient morbidity rate in the present study was $44.7 \%$, and the major complication rate was $12.5 \%$, both of which did not significantly differ based on the month of admission. Generally speaking, ASD surgery is considered a highly morbid procedure, with overall complication rates ranging from $40 \%$ to $86 \%$ in the literature. ${ }^{13,14}$ On the other hand, Schawb et al. conducted a multi-center review of 953 ASD patients, finding a "major" complication rate of 8.4\%. ${ }^{15}$ The most common complications found in their study were excessive blood loss (over 4 liters), deep wound infection, and pulmonary embolism. ${ }^{15}$ Identified risk factors for complication occurrence were staged procedures and combined anteriorposterior procedures.

For the aforementioned reasons, it could be argued that performing such operations at the commencement of the academic year with new trainees (particularly upcoming senior residents and spine fellows) may put patients at higher risk for complications and mortality. Interestingly, no differences were found in relation to these outcomes, suggesting that undergoing ASD surgery at the beginning of the academic year in July has insignificant impact on inpatient morbidity and mortality. These findings were also true after performing a subanalysis on patients admitted in July-August and for patients undergoing "complex" procedures such as osteotomy, fusion of 8 or more levels, revision procedures, or patients with a comorbidity score of 3 or higher. The absence of a "July effect" for ASD surgery may have several explanations. First, ASD surgery typically involves an attending surgeon with one or two assistants. ${ }^{11}$ Second, the steep learning curves of pedicle screw placement and correction maneuvers do not usually allow for a new senior resident or fellow to perform these procedures without adequate supervision. ${ }^{11}$ Lastly, postoperative care is done by a multidisciplinary team of surgeons, internists, anesthesiologists, intensive care specialists, pain managers, and others; it is likely that this approach compensates for any potential shortcomings (i.e. lack of training or experience) occurring with the influx of new staff in July.

The NIS is the largest inpatient database in the United States, and allows for examination of thousands of admissions, something that is not usually possible 
with single institution case series or even multicenter collaborations. Additionally, the inclusion of data such as race, primary payer, and comorbidities allows for adequate multivariable regression analyses. Nonetheless, this study has various limitations. First, the NIS does not include information on presenting symptoms, neurological status, sagittal/coronal balance, and others that may potentially influence patient outcomes. Second, there is the risk of miscoded data, but numerous studies have used this database for spinal surgery research ${ }^{2,6,17}$ and it is also unlikely that if it were the case, that data miscoding would only affect a specific month. Third, outcomes beyond the inpatient period are not recorded in this database, and prospective studies with longer follow-up are encouraged. Lastly, though the NIS clearly distinguished between teaching and nonteaching hospitals, it is a sample of community hospitals, so capture of traditional academic setting may not be occurring. Additionally, there is no information regarding the presence of resident, fellow, or cosurgeons during the operative procedure.

\section{Conclusion}

In this nationwide study examining outcomes of patients undergoing surgery for ASD at teaching hospitals, it was found that the involvement of new staff in July does not increase the rates of total complications, major complications, or inpatient mortality compared to patients admitted in other months.

\section{References}

1. Alshekhlee A, Walbert T, DeGeorgia M, Preston DC, Furlan AJ. The impact of Accreditation Council for Graduate Medical Education duty hours, the July phenomenon, and hospital teaching status on stroke outcomes. J Stroke Cerebrovasc Dis. May-Jun 2009;18(3):232-238.

2. Dasenbrock HH, Clarke MJ, Thompson RE, Gokaslan ZL, Bydon A. The impact of July hospital admission on outcome after surgery for spinal metastases at academic medical centers in the United States, 2005 to 2008. Cancer. Mar 1

2012;118(5):1429-1438.

3. Inaba K, Recinos G, Teixeira PG, et al. Complica- tions and death at the start of the new academic year: is there a July phenomenon? J Trauma. Jan 2010;68(1):19-22.

4. Jen MH, Bottle A, Majeed A, Bell D, Aylin P. Early in-hospital mortality following trainee doctors' first day at work. PLoS One. 2009;4(9):e7103.

5. Kestle JR, Cochrane DD, Drake JM. Shunt insertion in the summer: is it safe? J Neurosurg. Sep 2006;105(3 Suppl):165-168.

6. McDonald JS, Clarke MJ, Helm GA, Kallmes DF. The effect of July admission on inpatient outcomes following spinal surgery. JNeurosurg Spine. Mar 2013;18(3):280-288.

7. Phillips DP, Barker GE. A July spike in fatal medication errors: a possible effect of new medical residents. J Gen Intern Med. Aug 2010;25(8):774-779.

8. Smith ER, Butler WE, Barker FG, 2nd. Is there a "July phenomenon" in pediatric neurosurgery at teaching hospitals? J Neurosurg. Sep 2006;105(3 Suppl):169-176.

9. Buchwald D, Komaroff AL, Cook EF, Epstein AM. Indirect costs for medical education. Is there a July phenomenon? Arch Intern Med. Apr 1989;149(4):765-768.

10. Yaghoubian A, de Virgilio C, Chiu V, Lee SL. "July effect" and appendicitis. J Surg Educ. May-Jun 2010;67(3):157-160.

11. Hoashi JS, Samdani AF, Betz RR, Bastrom TP, Harms Study G, Cahill PJ. Is there a "July effect" in surgery for adolescent idiopathic scoliosis? J Bone Joint Surg Am. Apr 2 2014;96(7):e55.

12. Haller G, Myles PS, Taffe P, Perneger TV, Wu CL. Rate of undesirable events at beginning of academic year: retrospective cohort study. $B M J$. 2009;339:b3974.

13. Baron EM, Albert TJ. Medical complications of surgical treatment of adult spinal deformity and how to avoid them. Spine (Phila Pa 1976). Sep 1 2006;31(19 Suppl):S106-118.

14. Lapp MA, Bridwell KH, Lenke LG, et al. Longterm complications in adult spinal deformity patients having combined surgery a comparison of primary to revision patients. Spine (Phila Pa 1976). Apr 15 2001;26(8):973-983.

15. Schwab FJ, Hawkinson N, Lafage V, et al. Risk factors for major peri-operative complications in adult spinal deformity surgery: a multi-center review 
of 953 consecutive patients. Eur Spine J. Dec

2012;21(12):2603-2610.

16. Elixhauser A, Steiner C, Harris DR, Coffey RM. Comorbidity measures for use with administrative data. Med Care. Jan 1998;36(1):8-27.

17. Bydon M, De la Garza-Ramos R, Macki M, Desai A, Gokaslan AK, Bydon A. Incidence of sacral fractures and in-hospital postoperative complications in the United States: an analysis of 2002-2011 data.

Spine (Phila Pa 1976). Aug 15

2014;39(18):E1103-1109.

\section{Disclosures}

The authors declare no relevant disclosures or con- flicts of interest.

\section{Corresponding Author}

Daniel M. Sciubba, M.D., The Johns Hopkins Hospital, 600 North Wolfe Street, Meyer 5-185, Baltimore, Maryland 21287. dsciubb1@jhmi.edu

Published 8 January 2016.

This manuscript is generously published free of charge by ISASS, the International Society for the Advancement of Spine Surgery. Copyright $\odot 2016$ ISASS. To see more or order reprints or permissions, see http://ijssurgery.com. 